\title{
Emprego da metodologia da problematização no estudo da dificuldade de produção escrita entre alunos do ensino superior
}

\section{The application of the methodology of problematization in studying the difficulty in writing among university students}

\author{
Carla Rosane Paz Arruda Téo* \\ Silvia Renata Machado Coelho**
}

\section{Resumo}

\begin{abstract}
Com o objetivo inicial de exercitar o emprego da Metodologia da Problematização foi realizado o presente trabalho. Seguindo as etapas desta metodologia foi definido para estudo o problema da dificuldade de produção escrita entre alunos do ensino superior, fato que gera preocupação entre docentes das mais diversas áreas por ser esta uma habilidade fundamental para o bom desempenho dos futuros profissionais formados. Os resultados encontrados permitiram inferir que os alunos do ensino superior não apresentam hábito de leitura, o que não os torna aptos para a leitura crítica, culminando com uma acentuada dificuldade de produção escrita. Conclui-se que somente será possível amenizar o problema estudado mediante esforço coletivo do corpo docente, no sentido de implantar na rotina acadêmica situações reais de incentivo à leitura crítica e à produção escrita. Pelo exercício com a Metodologia da Problematização foi possível concluir que a mesma deve ser difundida, já que oportuniza contribuições efetivas às realidades trabalhadas, através da fase de aplicação prática, quando os autores assumem seu compromisso de ação transformadora.
\end{abstract}

Palavras Chave: Metodologia da Problematização, Leitura, Interpretação, Produção Escrita.

\begin{abstract}
This reserch was carried out aiming at practicing the Methodology of Problematizaton. Following the stages of this methodology the problem of the difficulty in the writing practice among university students was chosen to the studied. This fact concerns professors in general, once the ability of writing is considered as an essential one for all professionals. The results of this study showed that the university students are not used to reading. This fact causes great deficiencies in interpretation and writing abilities. It's possible to infer that only an effort from all professors can assuage the problem through the practice of reading and writing during the classes and examinations. We came to the conclusion that the exercise with the Methodology of Problematization must be disseminated, once this methodology leads to important contributions to the observed realities, through practice.

Keywords: Methodology of Problematization, Reading, Interpretation, Writing Practice.
\end{abstract}

\footnotetext{
* Nutricionista, Mestranda em Ciência de Alimentos/UEL, Coordenadora do Curso de Nutrição da Universidade Paranaense UNIPAR/Campus Toledo - Av. Parigot de Souza, 3636 - Jardim Prada - Toledo/PR - 85900000.

** Enga . Agrônoma, Mestre em Ciência e Tecnologia de Alimentos/UFG, Doutoranda em Ciência de Alimentos/UEL, Professora do Curso de Nutrição da Universidade Paranaense - UNIPAR/Campus Toledo.
} 


\section{Introdução}

A Metodologia da Problematização foi originalmente proposta por Maguerez (apud BORDENAVE; PEREIRA, 1982) sob a denominação de Método do Arco, apresentando a configuração ilustrada pela Figura 1.

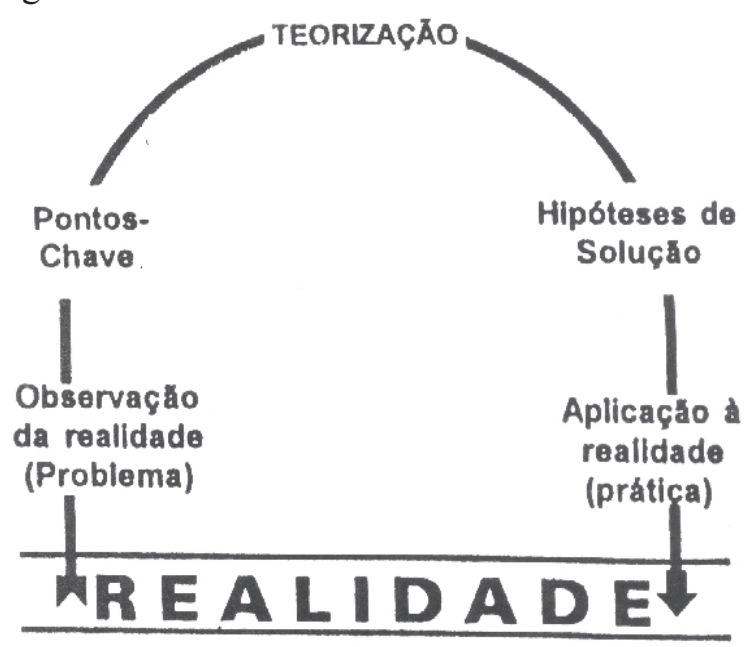

Figura 1: Etapas da Metodologia da Problematização

O Arco de Maguerez, representativo da Metodologia da Problematização, traz a realidade como seu ponto de partida e de chegada. No dizer de Berbel (1996), a metodologia concretiza-se através de um processo criativo de ação-reflexão sobre um determinado aspecto extraído da realidade observada e, como conseqüência deste processo, alguma transformação deverá ser intencionalmente provocada, de modo a amenizar ou solucionar uma situação-problema detectada.

Diversos estudos empregando a Metodologia da Problematização têm sido apresentados, indicando que a mesma é alternativa eficaz e viável para o processo ensino-aprendizagem, representando não a única, mas uma das ferramentas para a efetiva construção do saber. Segundo Berbel (1995), a Metodologia da Problematização oportuniza o desenvolvimento da capacidade de enfrentar problemas, propondo-lhes soluções viáveis. Atualmente, esta capacidade, por assim dizer, é tida e reconhecida como uma das principais competências esperadas dos profissionais das mais diversas áreas.
A Metodologia da Problematização, portanto, vem surgindo e se estabelecendo como instrumental eficiente para o processo de ensino-aprendizagem, em decorrência da necessidade de inovações metodológicas capazes de favorecer a formação de profissionais articulados e compromissados com o contexto sócio-político e histórico em que estão inseridos (GUARIENTE, 1996). Afinal, uma vez concluído o ensino superior, os indivíduos necessitarão apresentar habilidades e competências tais que os qualifiquem para o exercício profissional consciente e comprometido em suas áreas de atuação específicas.

Assim, exercendo a docência no ensino superior, colocamo-nos na posição de aprendizes e, com o objetivo inicial de exercitar o emprego da Metodologia da Problematização, realizamos o trabalho ora apresentado.

Seguindo as etapas da metodologia empregada, observamos atentamente nossa realidade e identificamos o problema mencionado no título deste trabalho: "Por que os alunos do ensino superior apresentam tão acentuada dificuldade de produção sob forma escrita?” Partindo desta etapa, conforme descreve a metodologia, comprovamos a afirmação de Berbel (1996): “O estudante é levado a ficar mais atento e observar o que ocorre na realidade próxima." $\mathrm{Na}$ posição de aprendizes, percebemos o quanto exercitamos a observação, buscando alguma situação-problema para a qual pudéssemos contribuir favoravelmente.

Após, exploramos o problema na busca por seus determinantes diretos e contextuais, a partir dos quais definimos os pontos-chave do estudo, refletindo sobre os aspectos provavelmente a ele relacionados.

Na etapa seguinte, a da teorização, aprofundamos o estudo dos pontos-chave do problema, utilizando como referências a literatura pertinente, o nosso conhecimento prévio sobre o assunto e informações colhidas junto à população delimitada para o trabalho em questão. Ou seja, esta fase se caracteriza pela busca sistematizada de informações (técnicas, científicas, empíricas, oficiais) sobre o problema em estudo (BERBEL, 1996). 
$\mathrm{Na}$ fase subseqüente, refletimos sobre as hipóteses de solução para o problema enunciado. Esta fase, segundo Berbel (1995), se beneficia do estímulo à criatividade e à originalidade, pois o problema elencado para estudo só existe em função de que a realidade observada o permite. Portanto, é fundamental, neste momento, pensar e agir de forma criativa e inovadora, rompendo com os paradigmas vigentes, objetivando a sua superação.

Finalmente, na fase de aplicação à realidade, descrevemos e assumimos nosso compromisso de ação transformadora frente à realidade observada, no intuito de contribuir para solucionar ou amenizar o problema que estudamos. É importante ressaltar que, nesta etapa, é preciso tomar decisões com base em critérios bem definidos, uma vez que esta é a fase da intervenção propriamente dita, devendo esta intervenção estar centrada em ações exeqüíveis e efetivamente viáveis (BERBEL, 1995, 1996).

Em suma, assumimos nossa condição de eternos aprendizes e exercitamos a Metodologia da Problematização. Porém, como profissionais, pudemos perceber de imediato os resultados deste exercício na nossa prática diária, conforme descrito no decorrer deste estudo.

\section{Observação da realidade}

A preocupação com a questão da produção de textos é, há muito, motivo de discussões entre os professores universitários nas mais variadas áreas do saber, uma vez que esta é uma habilidade fundamental para o bom desempenho escolar, assim como para toda e qualquer prática social.

Saber ler e escrever, já entre os gregos e romanos, significava possuir as bases de uma educação adequada para a vida; educação essa que visava não só ao desenvolvimento das capacidades intelectuais e espirituais, como das aptidões físicas, possibilitando ao cidadão integrar-se efetivamente à sociedade [...] dos homens livres. (MARTINS, 1985, p.22).
Praticando a docência em instituição privada de ensino superior e acompanhando uma mesma turma por dois anos consecutivos, pudemos constatar que é notável a dificuldade apresentada por estes alunos no que se refere à expressão escrita, ou seja, à produção de textos, por menores que estes possam ser. Assim, percebemos que os alunos não conseguem produzir respostas dissertativas ou descritivas coerentes, evidenciando carência de criatividade, de argumentação, de vocabulário e de cultura geral.

Com base na observação deste fato, justificamos nossa preocupação com os profissionais que estamos formando. Afinal, os mesmos serão solicitados, na sua prática diária, a expressar-se claramente tanto sob forma escrita como oral. Acreditamos, pois, ser nossa responsabilidade ajudá-los a conhecer as causas de suas dificuldades, a fim de que elas possam ser superadas.

Buscando melhor conhecer este universo de alunos, ao qual passaremos a chamar de Turma A, observamos que o grupo constitui-se de cerca de 50 alunos, dos quais $94,0 \%$ pertencem ao sexo feminino. A idade, dentro do grupo, varia de 18 a 38 anos e cerca de $50,0 \%$ dos alunos são casados. Uma característica a ser destacada nesta Turma A é a que se refere ao tempo decorrido entre o término do ensino médio e o ingresso na Universidade, o qual varia de zero a quinze anos, ou seja, alguns alunos terminaram o ensino médio e ingressaram na Universidade no ano seguinte, enquanto outros estiveram por até quinze anos fora dos bancos escolares. Quanto à classe social, percebemos que os alunos pertencem a diversos níveis econômicos, alguns, inclusive, cursando o ensino superior com dificuldades financeiras e com auxílio de bolsas de estudo e crédito educativo. Com relação ao tipo de estabelecimento de ensino onde realizaram o ensino médio, muitos alunos são oriundos de escolas públicas e outros tantos de escolas privadas, sem predomínio de uma situação ou de outra.

Dado este conjunto altamente heterogêneo de indivíduos e a situação exposta acima, percebemos que 
os alunos da Turma A têm um problema em comum e assumimos nossa parcela de responsabilidade na exploração deste problema, de forma que possamos contribuir para amenizá-lo.

\subsection{Definição do Problema}

Dentre outros aspectos dificultadores da formação profissional que pretendemos para nossos alunos, objetivamos, no momento, buscar respostas para o seguinte problema:

"Por que alunos do ensino superior apresentam tão acentuada dificuldade de expressão sob forma escrita?"

\section{Pontos-chave}

Ao nos desafiarmos com o problema formulado e refletindo sobre ele, elencamos alguns fatores que acreditamos estarem associados à sua existência.

Assim, um dos primeiros fatores que relacionamos à dificuldade de escrita é a dificuldade de interpretação. Ou seja, quando os alunos lêem uma questão proposta, não conseguem interpretá-la realmente, situando-se apenas no nível da decodificação pura e simples das palavras. Não atingindo uma interpretação satisfatória, não produzem respostas coerentes às proposições feitas.

Um outro fator que apontamos, dentre os mais diretamente associados ao problema descrito, é a pouca prática de escrita, já que os alunos normalmente não são exigidos em termos desta habilidade. Durante o ensino médio, último estágio antes do ingresso na Universidade, prioriza-se grandemente a capacidade de assinalar a resposta correta dentre diversas alternativas oferecidas, visando o vestibular. Uma vez cursando a educação superior, os alunos se deparam com muitos professores que continuam a se utilizar deste expediente, dito objetivo, como forma de avaliação, perpetuando-se a falta de exercício da escrita. Paralelamente, principalmente nos cursos de graduação das áreas de Ciências Exatas, da Saúde e Biológicas, verifica-se uma certa desvalorização das disciplinas da área de Ciências Humanas presentes nas matrizes curriculares. Porém, estas são, precisamente, as disciplinas que propiciariam uma maior oportunidade de leitura, interpretação e escrita.

Salientamos, ainda, um outro fator que pode estar diretamente associado ao problema explorado: a pouca disponibilidade de tempo dos alunos para a prática das habilidades de leitura, interpretação e escrita, já que o curso de graduação freqüentado pelos alunos-alvo deste trabalho se realiza em período integral. A falta do hábito de leitura, associada à pouca disponibilidade de tempo para leitura, agrava ainda mais o problema.

Porém, estamos certos de que, por trás destes fatores causais mais diretamente determinantes do problema, existem algumas outras questões que merecem ser abordadas por serem de maior amplitude no contexto da questão estudada. Neste sentido, questionamo-nos:

- Como se desenvolve o hábito da leitura e como ela se relaciona com as habilidades de interpretação e produção de textos?

- Qual o papel da escola, do professor e do Estado no desenvolvimento destas habilidades de leitura, interpretação e escrita por parte dos alunos?

- Até que ponto nossa população, com tantos analfabetos, conhece o valor da leitura e da escrita?

- Até que ponto a economia do país prioriza, efetivamente, a escolarização e o desenvolvimento do hábito da leitura?

Ao discutirmos estas questões, chegamos a um denominador comum: a ausência do hábito de leitura é um determinante contextual fundamental do problema estudado, uma vez que seu desenvolvimento passa pela formação do aluno na totalidade de sua vida acadêmica, tendo importante influência da família. Além do mais, ler decodificando símbolos não é alternativa que se possa considerar suficiente: é preciso que o hábito de leitura esteja perpassado pela 
interpretação para que o leitor, crítico, seja capaz de produção escrita de qualidade.

Considerando-se o já discutido, destacamos alguns pontos-chave para estudo e uma reflexão mais aprofundada:

$\boldsymbol{O}$ Hábito de Leitura, como mencionamos anteriormente, é determinante maior das habilidades de interpretação e escrita.

[...] há uma relação entre ler e escrever, de tal forma que uma prática leva à outra, num processo permanente; evidentemente, essa relação não é automática, direta e necessária, mas a escrita interfere na constituição do leitor e a leitura determina as formas de escrever (SUASSUNA, 1995, p.155).

Mas o que é leitura? Como se desenvolve? Quando se aprende a ler? Que papel tem a leitura como agente transformador? Quais são os elementos fundamentais na formação do leitor? Qual a importância da leitura para o indivíduo e para a sociedade?

Interpretação é uma habilidade decorrente da leitura ativa e determinante da escrita, mas como ela se relaciona com a leitura de mundo de cada um? Quais são os níveis de conhecimento envolvidos no exercício da interpretação? Quais são os níveis de análise de textos? Como a habilidade de interpretação impacta na formação de um verdadeiro cidadão?

\section{A Produção de Textos é habilidade fundamental para qualquer acadêmico, futuro profissional, mas como ela se relaciona com a leitura e com a inter- pretação? Quais são as características de um tex- to? Como se desenvolve a habilidade de escrita ao nível da verdadeira produção de textos?}

\section{Teorização}

Ao decidirmos estudar o problema definido no item 1.1 ("Por que alunos do ensino superior apre- sentam tão acentuada dificuldade de expressão sob forma escrita?”), passamos a explorá-lo, buscando informações que pudessem trazer elementos para sua solução.

Com o aprofundamento da reflexão, percebemos que os determinantes se apresentam muito inter-relacionados e, por este motivo, são, a seguir, abordados no seu conjunto.

\subsection{A Leitura: Um Breve Histórico}

A necessidade de se expressar fez com que o homem criasse uma forma própria de se comunicar. $\mathrm{O}$ homem primitivo registrava suas idéias através de desenhos. Assim, a fala representava as idéias e os desenhos (escrita primitiva) representavam a fala.

Pouco a pouco, a leitura e a escrita tornaram-se práticas necessárias, critérios para o ingresso e para a participação do indivíduo na sociedade, passando a existir, de um lado, o homem alfabetizado e culto; do outro, o analfabeto e, portanto, ignorante.

Diante desta situação, aquele que não era leitor encontrava-se na condição primitiva da fala, sem condições de ascender socialmente. Assim, segundo Zilberman (1998, p.4), "uma história da leitura faz parte, portanto, da história capitalista".

Apesar desta necessidade de leitura e escrita rumo à ascensão social, apenas com o surgimento da imprensa, em 1434, o povo passou a ter acesso aos livros. Desta forma, os mosteiros e conventos, que mantinham o monopólio sobre os bens culturais, perderam esta exclusividade e, nas cidades, passaram a se organizar corporações de escribas e livreiros.

Também o surgimento das Universidades foi fator relevante para o incentivo e desenvolvimento do público leitor. Houve, assim, um impulso maior à produção e transmissão de textos escritos. Todavia, este impulso não garantiu que todos tivessem acesso ao mundo da leitura, universo que ainda pertencia a um pequeno grupo privilegiado.

Com o Renascimento veio a valorização do clássico, isto é, do homem, de sua força física e mental, 
estimulando-se a gradativa renovação cultural. Nesta época, as Universidades tinham por objetivo ampliar e transmitir às classes dominantes o conhecimento necessário à prática do mercantilismo. Assim, neste período surgiu a distância que persiste até hoje entre a minoria culta e a maioria inculta.

Com o século XVIII algumas mudanças ocorreram. A burguesia fortalecida controlava a economia européia baseada na força da Revolução Industrial. Esta burguesia representava o público leitor e a leitura era vista não só como meio de apropriação de conhecimento, mas também como fonte de prazer. $\mathrm{O}$ número de leitores aumentou.

Assim, o homem foi vencendo barreiras ao longo de sua história. Hoje, diante da facilidade de comunicação que a tecnologia nos trouxe, cada indivíduo deve se apropriar de todas as vantagens possíveis na aquisição de conhecimentos e habilidades. Nas palavras de Silva (1993, p.57), "não só podemos, como também devemos perguntar tudo a todos. Perguntamos a nós mesmos, aos colegas, aos professores, aos livros, às revistas, aos jornais, ao rádio, à televisão, aos computadores". E, se assim não for, estes instrumentos passarão a ser ferramentas de discriminação social, pois os mesmos serão entraves para a integração do indivíduo ao mundo da comunicação.

\subsection{Um Conceito de Leitura}

Freqüentemente acontece de entender-se por leitura o simples "passar os olhos", a partir do qual nada de pessoal é desencadeado além da decodificação de sinais. É a leitura superficial.

A leitura superficial se dá quando o leitor não interage com o objeto de leitura: é como se não tivesse nenhum interesse no seu conteúdo, como se este conteúdo não the dissesse respeito, ou não tivesse nenhuma contribuição a lhe dar.

Para que se possa entender por que não se vê sentido (ou não se tem interesse) em determinados tipos de leitura, é preciso refletir sobre "como e quando um indivíduo começa a ler”.
O ser humano entra em contato com a leitura desde o berço, com as sensações primeiras que experimenta no seu pequeno universo. Este processo de contato com a leitura avança pela sua vida inteira, passando pela infância, quando se aventura num mundo ainda desconhecido, e é enriquecido pelas trocas que realiza com outros seres humanos. Esta é a leitura de mundo.

Este aprendizado o indivíduo realiza na convivência que estabelece com outros indivíduos ao longo de sua vida, pois, segundo Freire (1994, p.12), "os homens se educam em comunhão, mediados pelo mundo".

Neste contexto, ler verdadeiramente não significa decifrar palavras: podemos ler gestos, podemos ler o tempo, o olhar, o espaço. Ler é muito mais do que, simplesmente, decodificar sinais. Além disso, um mesmo fato pode ser lido de maneiras completamente diversas, em função do momento ou do contexto em que se dá a leitura do acontecido.

Ainda segundo Freire (1994), a leitura da palavra é precedida de uma leitura de mundo e de uma certa forma de reescrevê-lo. Ou seja, a leitura realmente se concretiza quando, através dela, o indivíduo entende os dados da realidade, analisa-os e transforma-os a partir de uma prática consciente para o seu próprio bem.

\subsection{O Papel Transformador da Leitura}

Como toda produção humana, a língua acontece e se desenvolve em um contexto social específico e seu desempenho é resultante deste universo onde o indivíduo está inserido e das influências e estímulos aos quais o mesmo é exposto desde o seu nascimento. Neste processo, é preciso que o indivíduo não só desenvolva a sua leitura de mundo, mas que seja capaz de fazer a sua própria "escrita do mundo". Ou seja, é preciso aprender a localizar problemas, verificar suas causas e agir de forma a transformar situações. 
Ler não é decifrar, como num jogo de adivinhações, o sentido de um texto. É, a partir do texto, ser capaz de atribuir-lhe significação, conseguir relacioná-lo a todos os outros tipos de textos significativos para cada um, reconhecer nele o tipo de leitura que seu autor pretendia e, dono da própria vontade, entregar-se a esta leitura, ou rebelarse contra ela, propondo outra não prevista. (LAJOLO, 1982, p.59).

Assim, a maturidade é fundamental para a concretização da verdadeira leitura, da leitura transformadora. Esta maturidade só pode ser construída na intimidade com o texto, com muitos textos, formando-se algo como que um "banco de dados", enriquecido e alimentado a cada nova leitura, a cada nova idéia analisada, de forma que pode se alterar o sentido de tudo que já se leu antes, ou não. Nesta vivência de leitura, o indivíduo compreende o objeto de sua leitura, seja ele um livro, ou pessoas, ou a vida. A partir da compreensão, este leitor é capaz de posicionar-se e atuar. Ou seja, ele estabelece relações entre as diversas experiências vivenciadas, buscando resolver problemas, entendendo o mundo e tentando transformá-lo.

\subsection{Elementos Fundamentais na Formação do Lei- tor}

A leitura e a escrita têm sido apontadas como responsáveis, pelo menos em parte, pelo alto índice de reprovação escolar nas diversas fases da vida acadêmica. Na Turma A, objeto desencadeador deste estudo, as dificuldades de leitura e escrita têm, comprovadamente, gerado um certo "fracasso" escolar, visto que muitos alunos reprovados nas avaliações oficiais demonstravam aprendizado adequado quando argüidos oralmente. Por este motivo, a questão da formação de leitores e a reflexão sobre os elementos envolvidos nesta formação apresentam-se prioritárias.

\subsubsection{A Família}

O aprendizado vem sempre através do exemplo e a instrução é apenas um reforço das experiências anteriores adquiridas na família.

As crianças aprendem desde o momento que vêm ao mundo. Uma criança aprende ouvindo conversas de sua mãe, dentro e fora de casa. (...) Ela sempre aprende com o objetivo de atribuir significado a alguma coisa e, especialmente, quando existe um exemplo, um modelo a ser seguido. (SILVA, 1994, p.56).

Assim, uma criança só aprende algo que tem significado em seu ambiente e "grande parte da aprendizagem humana ocorre da observação do comportamento de outras pessoas" (SILVA, 1993, p.56). Logo, se a família tem o hábito de ler, se possui livros ou tem acesso a eles, se há modelos ou exemplos de leitura no lar, a criança percebe a função social do ato de ler, incorporando este comportamento.

Procurando conhecer o impacto que o núcleo familiar teve no desenvolvimento do hábito de leitura de nossos alunos, solicitamos que os mesmos respondessem a um questionário (apresentado como Anexo 1), o qual contemplou não só este, mas diversos outros elementos que consideramos relevantes para nosso estudo.

Assim, a partir de informações colhidas junto aos nossos alunos, observamos que cerca de $59,0 \%$ referiu ter pelo menos um familiar próximo que apresenta o hábito da leitura e $90,0 \%$ respondeu que recebe ou recebeu incentivo à leitura por parte de sua família, sendo que 48,0\% apontou ter aprendido a ler antes de seu ingresso na primeira série do ensino fundamental e $82,0 \%$ dos entrevistados relatou possuir em suas casas um local apropriado para leitura. Porém, cerca de $70,0 \%$ destes mesmos entrevistados respondeu que dedica menos de uma hora por dia à atividade de leitura, priorizando basicamente revistas semanais e jornais.

Perguntamo-nos se o conceito de "hábito de leitura" empregado por nossos alunos ao responder nossos questionamentos equivale ao nosso, pois nos parece incoerente que, com um número tão expressivo de alunos que se acreditam incentivados à leitura, tenhamos um índice de dedicação a esta atividade tão baixo, em termos de horas de leitura por dia. 
De toda maneira, é claro que outros aspectos também estão estreitamente relacionados com a formação do leitor.

\subsubsection{A Escola}

O patrimônio histórico, cultural e científico da humanidade se encontra registrado nos livros. Deste modo, cabe à escola desenvolver o potencial do educando, formando e preparando leitores críticos que tenham verdadeiro acesso a este patrimônio. Logo, a escola deve viabilizar o ingresso do aluno no mundo dos textos, estimulando-o a produzí-los e a interpretá-los. Mas como a escola pode fazer isto? Bem, a escola precisa manter estímulos à formação do leitor, como biblioteca adequada, currículo que oportunize a seqüenciação e a integração das habilidades e conteúdos de leitura, além de momentos e espaço físico para que estas atividades aconteçam de maneira eficiente, satisfatória e envolvente para o educando.

Questionados no que tange a este elemento tão importante na formação do leitor, os entrevistados responderam que vivenciaram situações de incentivo à leitura, principalmente entre a $6^{\mathrm{a}} \mathrm{e}$ a $8^{\mathrm{a}}$ séries do ensino fundamental $(59,0 \%)$ e durante as séries do ensino médio $(56,0 \%)$.

Mais uma vez, paramos para uma breve reflexão e perguntamo-nos: pelo que experimentaram em suas vidas escolares pregressas, o que nossos alunos entendem, verdadeiramente, por "incentivo à leitura"?

\subsubsection{O Professor}

Pelo contato direto que tem com o aluno, o professor é fonte importante de exemplo para o mesmo, sendo um dos principais responsáveis pela formação do leitor.

A conduta do professor como leitor, portanto, é referencial de leitura para o aluno. Seu entusiasmo pela leitura é estímulo essencial para a formação do leitor.
Neste sentido, cabe ao professor encaminhar a prática pedagógica, selecionando textos significativos para seus alunos, incentivando-os ao uso da biblioteca, apontando fontes para os assuntos estudados e, principalmente, demonstrando prazer pela leitura. Só assim o aluno se sentirá motivado e poderá se tornar um leitor competente.

Indagados sobre esta questão, $88,5 \%$ dos alunos entrevistados respondeu ter atualmente ou já ter tido anteriormente um professor que incentivasse o hábito de leitura, fosse por suas palavras ou por suas atitudes.

\subsubsection{O Estado}

De acordo com a Constituição da República Federativa do Brasil, ao Estado cabe proporcionar aos estudantes a formação necessária para o desenvolvimento de suas potencialidades físicas e intelectuais. O poder público tem, desta forma, uma inegável responsabilidade para com a educação em geral, a fim de propiciar o verdadeiro exercício da cidadania.

O Estado deve assegurar, portanto, excelência na educação, priorizando a educação na destinação de verbas públicas e exigindo das escolas privadas a manutenção de um padrão pedagógico e estrutural mínimo de qualidade.

\subsection{Interpretação: A Verdadeira Face da Leitura}

Com base em tudo o que foi exposto até agora, podemos dizer que a verdadeira leitura, quando o leitor criticamente analisa o objeto lido e se posiciona a respeito dele, sendo capaz de agir de forma transformadora, começa pela leitura interpretativa. Logo, a interpretação do objeto de leitura é habilidade fundamental do leitor crítico.

Por terem dificuldade acentuada de interpretação, os alunos de ensino superior da Escola estudada não fornecem respostas dissertativas coerentes quando solicitados, fugindo muito do "caminho da resposta". 
Inclusive, de um total de 44 alunos entrevistados, $77,0 \%$ relatou sentir algum grau de dificuldade no que se refere à interpretação de questões propostas em avaliações no curso de graduação freqüentado.

Observando esta dificuldade e acreditando na sua importância, dado o problema estudado, convém que nos detenhamos um pouco em alguns aspectos da habilidade de interpretação.

3.5.1 Níveis de Conhecimento Envolvidos no Processo de Interpretação

O processo de interpretação é altamente complexo e exige do leitor, além de exercício constante, três níveis de conhecimento, segundo Kleiman (1997):

- Conhecimento Lingüístico: nível de conhecimento implícito, não verbalizado, o qual abrange o conhecimento da pronúncia, do vocabulário, das regras da língua e do seu uso.

- Conhecimento Textual: conjunto de noções e conceitos sobre o texto, permitindo sua classificação em termos de estrutura e tipo de discurso.

- Conhecimento de Mundo: conhecimento adquirido no contato com o mundo e com os textos, quando "o leitor utiliza na leitura o que ele já sabe, o conhecimento adquirido ao longo de sua vida" (KLEIMAN, 1997, p.13).

Sobre o Conhecimento de Mundo, Koch e Travaglia (1991) postulam que ele é armazenado na memória em blocos, chamados modelos cognitivos, os quais os autores classificam como se segue:

- Frames: conjunto de conhecimentos que estão armazenados na memória e são ativados por associação, sem que haja ordenação entre eles; por exemplo, quando se fala em escola, ativa-se na memória: alunos, livros, professores, cadernos, etc.

- Esquemas: conjunto de conhecimentos armazenados em seqüência temporal ou causal; por exemplo, a seqüência de movimentos utilizada pelo motorista para colocar um automóvel em funcionamento.
- Planos: conjunto de conhecimentos sobre como agir para atingir um determinado objetivo; por exemplo, como proceder para produzir um texto dissertativo.

- Scripts: conjunto de conhecimentos sobre normas, costumes, comportamentos de uma determinada cultura; por exemplo, os rituais religiosos.

- Superestruturas ou Esquemas Textuais: conjunto de conhecimentos sobre a variada tipologia de textos que se adquire através do contato com a diversidade de textos e quando se faz comparações entre eles.

Portanto, podemos concluir que o entendimento de um objeto de leitura não se realiza verdadeiramente quando tomamos como referência apenas o texto a ser analisado. Um certo conhecimento prévio é fundamental para a interpretação, ou seja, a interação de diversos níveis de conhecimento permite ao leitor inferir o suficiente para a real compreensão do texto.

Desta forma, a leitura é uma atividade que exige do leitor compromisso e conhecimento, uma vez que nenhum objeto de leitura pode ser considerado um produto acabado a ser recebido passivamente pelo leitor (KLEIMAN, 1997).

\subsubsection{Níveis de Análise de Textos}

Invariavelmente, a prática de leitura tem priorizado a decodificação, limitando-se ao nível da leitura superficial e do domínio dos aspectos mecânicos, como velocidade de leitura, fluência e dicção, pouco preocupando-se com a interpretação de fato e com a interação leitor-autor.

No entanto, a verdadeira leitura é um processo dinâmico através do qual leitor e autor se relacionam por meio do texto escrito. Neste processo, o leitor decodifica sinais e lê, também, o que está implícito, o extralingüístico.

Assim, pode-se classificar a análise de textos em quatro níveis: 
- Decodificação: informações explícitas na superficialidade do texto; "é a leitura literal, letra a letra, fiel à superfície do texto, a que se detém num único significado, direto, imediato, comum" (MESERANI, 1995, p.43).

- Interpretação: leitura das informações que estão implícitas no texto; "interpretar é traduzir, explicar, aclarar significados obscuros, sugeridos ou plurais" (MESERANI, 1995, p.45). Em termos de interpretação, é preciso observar as "pistas" que o autor coloca estrategicamente no texto, mas a percepção destas pistas textuais depende do conhecimento adquirido pelo leitor através de outras leituras e de suas experiências: este é o processo de intertextualização, o qual proporciona a atribuição de significado ao texto.

- Confrontação: momento em que o leitor relaciona o texto lido aos dados da realidade e a outros textos. A fim de contestar ou confirmar informações e relativizar conceitos e posições.

- Argumentação: momento em que o leitor, amadurecidamente, assume uma posição sobre determinado tema, avaliando os aspectos positivos e negativos da questão; este momento é decorrente da leitura crítica.

Refletindo sobre o exposto, acreditamos que a leitura constitui ferramenta básica para a formação do leitor que seja capaz de interpretar não apenas o óbvio em um texto. Isto é, a prática da leitura bem orientada é elemento fundamental para a formação do leitor crítico, capaz de interpretar realmente um objeto de leitura.

\subsection{A Produção Escrita}

A produção escrita, indo desde uma simples resposta dissertativa até crônicas ou livros, está embasada em idéias, na formulação de opiniões e na tomada de posições. A leitura, seja de livros, revistas, ou jornais, é o instrumento que possibilita a reflexão sobre as idéias expostas, resultando na construção de opiniões e na tomada de posições sobre os mais diversos temas. Logo, ler e escrever são atividades inseparáveis: só escreve bem quem lê.

[...] o trabalho com a leitura é integrado à produção de textos em dois sentidos: de um lado ela incide sobre o que se tem a dizer (...) de outro lado, ela incide sobre as estratégias do dizer $[\ldots]$ (GERALDI, 1993, p.166).

Neste momento de nosso estudo, portanto, pensamos ser extremamente importante nos determos em algumas considerações sobre a produção escrita.

Buscando um conceito para "texto" (entendendo-se a palavra por toda produção escrita, independentemente de seu tamanho ou forma), encontramos em Val (1994) a afirmação de que um texto não é apenas uma seqüência de frases, na medida em que apresenta textualidade. Esta textualidade a que Val se refere é determinada por alguns fatores:

- Coerência: característica que confere sentido ao texto, envolvendo aspectos lógicos, semânticos, cognitivos.

- Coesão: é a unidade formal do texto, construída através de mecanismos gramaticais e lexicais.

- Intencionalidade: habilidade de produzir textos adequados à obtenção de determinados efeitos desejados; por exemplo: intenção de informar, de convencer, de impressionar, de ofender, de agredir, etc.

- Aceitabilidade: é a busca da interlocução, da interação autor-leitor, onde um se esforça por fazer-se compreender e o outro procura desvendar o sentido do texto, através de pistas textuais e de experiências prévias.

- Situacionalidade: é a adequação do texto à situação sociocomunicativa; o produtor utilizará recursos diferentes em situações diversas.

É preciso, ao construir um texto, verificar o que é adequado àquela situação específica: grau de formalidade (...), etc. O lugar e o momento da comunicação, bem como as imagens recíprocas que os interlocutores fazem uns dos outros, os papéis que 
desempenham, seus pontos de vista, objetivo da comunicação, enfim, todos os dados situacionais vão influir tanto na produção do texto, como na sua compreensão (KOCH; TRAVAGLIA, 1991, p.70).

- Informatividade: característica do texto de levar conhecimento ao leitor, informações novas apresentadas de forma a serem compreendidas dentro da expectativa do produtor (autor).

- Intertextualidade: necessária tanto para a produção quanto para a compreensão de um texto, a intertextualidade é o relacionamento do objeto de leitura (ou da produção) com experiências e leituras prévias; dá-se em nível de forma e/ou de conteúdo.

Analisando os elementos que conferem textualidade ao texto, é fácil percebermos a importância da experiência do produtor como leitor ativo para a construção escrita. Não há, de outra forma, como se redigir textos coerentes e coesos, sem clichês, frases feitas, afirmações sobre o óbvio.

Para coletar informações sobre a produção escrita, incluímos algumas perguntas no questionário que aplicamos a nossos alunos, a partir das quais obtivemos as seguintes informações: $15,0 \%$ dos alunos consultados afirmou ter vivenciado situações de incentivo à produção escrita entre a $6^{\mathrm{a}}$ e a $8^{\mathrm{a}}$ séries do ensino fundamental e $54,5 \%$ declarou ter vivenciado este tipo de situação durante o ensino médio; $63,5 \%$ dos alunos afirmou apreciar a atividade de escrita e $41,0 \%$ do total de consultados declarou exercer esta atividade através da elaboração de resumos na fase de preparação para as avaliações obrigatórias bimestrais. Ainda, do total de 44 alunos que responderam a nosso questionário, $73,0 \%$ classificou sua produção escrita como boa, 18,0\% como regular, $9,0 \%$ como excelente e nenhum entrevistado avaliou sua produção como ruim.

Com base nestas informações, podemos inferir que a prática escrita mais expressivamente exercitada por nossos alunos é a de elaboração de resumos, os quais não passam por correções, não são submetidos a avaliações e, portanto, não oferecem aos alu- nos a oportunidade de reconhecer e corrigir eventuais erros que possam cometer. Ou seja, os alunos acabam por incorporar e perpetuar determinadas deficiências de produção escrita, sem nem mesmo se conscientizarem de que as mesmas existem. Afinal, como os próprios alunos consultados relataram, a grande maioria deles $(82,0 \%)$ considera sua produção escrita entre boa e excelente.

\subsection{O Círculo Leitura-Interpretação-Produção}

Avaliando as referências encontradas na literatura disponível e observando nossa realidade, pudemos chegar a algumas considerações finais, as quais nos auxiliaram na proposição de hipóteses de solução.

A partir da leitura de Lajolo (1982), Geraldi (1993) e Suassuna (1995), podemos dizer que as habilidades de leitura, interpretação e produção escrita se interrelacionam num círculo sem fim. Isto é, o leitor crítico é aquele que interpreta, ou seja, é capaz de fazer a sua leitura própria do objeto de leitura. O leitor crítico é hábil e ávido por emitir suas posições e opiniões sob forma escrita, fazendo-o de forma coesa e coerente, no que depende de leituras e experiências prévias, anteriores.

Desta forma, o hábito de leitura contribui para o desenvolvimento das habilidades de interpretação e produção, pelo constante contato em que coloca o leitor com diversos tipos de texto. O leitor ativo, assim, vai acumulando experiências, conhecimentos, e vai construindo a sua própria leitura de mundo. Ao fazê-lo, torna-se capaz de fazer a sua "escrita de mundo". Neste momento, de acordo com Freire (1994), torna-se um cidadão, maduro o suficiente para exercer sua ação transformadora.

Neste processo de construção da cidadania, a família , citada por Silva (1994), e a escola desempenham papel fundamental e do qual não podem se eximir. O exemplo de familiares e professores é indispensável na motivação do indivíduo à leitura, desde a mais tenra idade. Adultos que não desenvolveram este hábito desde a infância apresentam, con- 
forme observamos, maiores dificuldades no estabelecimento do gosto e do interesse pela leitura, bem como das habilidades de interpretação e escrita.

Paralelamente, o Estado desempenha papel da maior relevância na construção da cidadania, uma vez que deve priorizar a educação verdadeiramente, através do investimento na infra-estrutura escolar, na capacitação de professores, na geração de empregos, no estabelecimento de salários compatíveis com um nível de vida minimamente condizente com a cidadania de que falamos até agora.

Infelizmente, o que observamos atualmente é um descaso por parte do governo a respeito da educação, limitando-se o mesmo a medidas pouco efetivas no sentido de verdadeiramente formar cidadãos comprometidos com a vida em sociedade e conscientes do seu papel na transformação desta sociedade.

A população, em grande parte, ainda desconhece o valor da verdadeira educação e o que se vê é a supervalorização do grau de escolaridade e dos títulos obtidos. Assim, cada vez mais proliferam oportunidades para que os indivíduos adquiram certificados de escolarização, sem que haja a efetiva formação do cidadão. Grande parte desta população ainda não valoriza a leitura e a diversidade na leitura como instrumentos importantes de educação. Tristemente, percebe-se que o governo mantém suas ações no nível numérico (índices de alfabetização, de reprovação, etc), sem demonstrar uma preocupação traduzida em ações sobre o aspecto qualitativo da educação.

Reforçando as valiosas informações obtidas na literatura, obtivemos algumas outras junto ao universo de alunos que nos motivou ao estudo deste problema. Deparamo-nos, então, com alguns dados aparentemente contraditórios.

Observamos que um expressivo contingente dos alunos entrevistados afirmou receber ou ter recebido incentivo à leitura por parte de suas famílias, de seus professores e das escolas freqüentadas, além de terem declarado possuir local apropriado para leitu- ra em suas casas. Por outro lado, a maioria das respostas fornecidas indica a ausência do hábito de leitura entre os entrevistados, dentre os quais também a maioria referiu dificuldades de interpretação em algum nível.

Prosseguindo em nossa investigação, percebemos que a maioria dos alunos acredita ter vivenciado situações de incentivo à escrita e demonstra apreço por esta atividade, embora pratiquem-na basicamente sob a forma de produção de resumos para seu próprio estudo.

Refletindo sobre estas informações, acreditamos que as expressões "hábito de leitura" e "incentivo à leitura" têm significados diversos para nós e para os nossos entrevistados. Talvez a prática pedagógica mais tradicional que a maioria, senão a totalidade, de nossos alunos tem experimentado nos bancos escolares não tenha permitido que os mesmos apreendessem o verdadeiro significado das expressões trabalhadas. Afinal, não faz parte de nossa história a formação de leitores críticos, de cidadãos.

Paralelamente, dificuldades na interpretação das questões propostas em nosso questionário podem ser a causa destes resultados também, pelo menos em parte.

De qualquer forma, avaliando de forma global as informações obtidas e confrontando-as com a literatura consultada, podemos afirmar e confirmar que os alunos que deram origem a este estudo não são leitores críticos (e, portanto, aptos à eficiente interpretação do objeto de leitura proposto), não apresentando, também, efetiva e producente prática de atividade de escrita. Agravando esta situação, percebemos que os entrevistados sequer têm consciência de seu problema, o que o torna, sob nosso ponto de vista, mais emergencial.

\section{Hipóteses de solução}

Preocupados com o problema estudado e refletindo sobre ele e seus possíveis determinantes, propusemos algumas hipóteses de solução, apresentadas a seguir: 
- Acreditamos veementemente que só o esforço coletivo do corpo docente poderá amenizar o problema anunciado neste estudo, através do incentivo à leitura, à interpretação e à escrita no desenvolvimento das atividades acadêmicas nas diversas disciplinas da grade curricular do curso de graduação ora em questão; propomos, neste sentido, reunir este corpo docente e discutir com ele a priorização das atividades acima mencionadas como rotina acadêmica;

- Propomos, ainda, o estabelecimento de um mínimo de questões dissertativas em todas as avaliações formais definidas pela Instituição como obrigatórias, de forma a garantir minimamente a exigência em termos de habilidades de interpretação e produção;

- Sugerimos, como hipótese de solução, também, a implementação de um projeto anual permanente (que envolva todos os alunos em sistema de rodízio), no qual se trabalhe especificamente a leitura, a interpretação e a produção escrita, utilizando-se textos variados, cuja escolha deverá ser discutida com cada grupo de alunos participante do projeto naquele momento.

\section{Aplicação prática}

A implementação das hipóteses de solução apontadas no item 4 é o começo da aplicação prática deste estudo. Colocando em prática aquilo a que nos propusemos, acreditamos que poderemos, brevemente, alcançar proporções maiores e atingir um número mais significativo de alunos e de professores comprometidos com a questão trabalhada.

Neste sentido, nos comprometemos a apresentar este trabalho ao corpo docente do Curso de Graduação estudado e a estabelecer com ele o número mínimo de questões dissertativas a ser incluído em cada avaliação obrigatória. Paralelamente, assumimos o compromisso de, ao realizar a apresentação deste estudo, estabelecer acordo com o corpo docente do Curso sobre a priorização das atividades de incenti- vo à leitura, à interpretação e à escrita como rotina acadêmica.

Comprometemo-nos, também, com a elaboração e a execução de um projeto de ensino permanente, $o$ qual abordará especificamente a leitura, a interpretação e a produção de textos diversos.

Finalmente, visando consolidar nosso compromisso de ação transformadora, comprometemo-nos com a disseminação deste trabalho, o que muito contribuirá, certamente, para amenizar o problema enunciado, uma vez que esta questão chegará, desta forma, a muitos outros docentes e alunos.

\section{Conclusão}

O exercício com a Metodologia da Problematização foi, sem dúvida, valioso para nossa formação docente e pessoal. Aplicando a Metodologia, pudemos assimilá-la, compreender seus mecanismos e, certamente, estaremos aptos para empregá-la em nossa prática diária.

Através deste exercício mergulhamos no estudo do problema enunciado, envolvemo-nos com ele e, mais do que isto, comprometemo-nos com ele. Podemos, mesmo, ousar dizer que a Metodologia da Problematização é apaixonante e que nos levou a um nível tal de intimidade e interesse pelo problema estudado, que não seria possível pararmos no meio do caminho.

Por isto, acreditamos que esta Metodologia deva ser difundida, disseminada. Pensamos que ela aparece como uma alternativa consistente tanto para o aprendizado, quanto para a efetiva melhora da qualidade de vida, pelos resultados que são alcançados a partir do seu emprego.

Um ponto que queremos destacar é o do compromisso assumido no desenvolvimento da Metodologia da Problematização de, ao término do trabalho, "devolver", "entregar" alguma contribuição à realidade estudada. Consideramos este aspecto extremamente importante, uma vez que o que normalmente se ob- 
serva são estudos, pesquisas, etc., sem melhoria das situações trabalhadas, como se os estudiosos explorassem uma dada realidade e trancafiassem o aprendizado que obtiveram com ela. Aqui, com a Metodologia da Problematização, acontece o contrário: estudamos, aprendemos, mas nos comprometemos a contribuir para solucionar ou amenizar problemas encontrados. Pensamos que este seja o caminho da evolução, em todos os sentidos, e que, desta forma, através deste compromisso, podemos contribuir para a construção e/ou para a consolidação da verdadeira cidadania.

\section{Agradecimentos}

Agradecemos à professora Dr ${ }^{\mathrm{a}}$. Neusi Aparecida Navas Berbel por, de forma tão competente, ter apresentado a Metodologia da Problematização a seus alunos da disciplina de Metodologia do Ensino Superior, no Curso de Mestrado e Doutorado em Ciência de Alimentos da Universidade Estadual de Londrina.

\section{Referências}

BERBEL, N. A. N. A Metodologia da Problematização no Ensino Superior e Sua Contribuição Para o Plano da Práxis. Semina: Ci. Soc./Hum., v.17, Ed. Especial, p.717, nov., 1996.

Metodologia da Problematização: Uma Alternativa Metodológica Apropriada Para O Ensino Superior. Semina: Ci. Soc./Hum., v.16, n.2, Ed. Especial, p.919, out., 1995.

BORDENAVE, J. D.; PEREIRA, A. Estratégias de Ensino-aprendizagem. 4.ed. Petrópolis: Vozes, 1982.

FREIRE, Paulo. A importância do ato de ler. São Paulo: Cortez, 1994.

GERALDI, João Wanderlei. Portos de Passagem. São Paulo: Martins Fontes, 1993.

GUARIENTE, M. H. D. M. Metodologia da Problematização: Alternativa Metodológica Viável Para a Disciplina de Fundamentos de Enfermagem? Semina: Ci. Soc./Hum., v.17, Ed. Especial, p.17-27, nov., 1996.

KLEIMAN, Ângela. Texto e Leitor: aspectos cognitivos da leitura. Campinas: Pontes, 1997.
KOCH, Ingedore Vellaça; TRAVAGLIA, Luiz Carlos. A coerência textual. São Paulo: Contexto, 1991.

LAJOLO, Marisa. Leitura em crise na escola. São Paulo: Mercado Aberto, 1982.

MARTINS, Maria Helena. O que é leitura. São Paulo: Brasiliense, 1985.

MESERANI, Samir. O intertexto escolar. São Paulo: Cortez, 1995.

SILVA, Ezequiel T. da. Elementos de Pedagogia da Leitura. São Paulo: Martins Fontes, 1994.

Leitura e Realidade Brasileira. Porto Alegre: Mercado Aberto, 1993.

SUASSUNA, Lívia. Ensino de Língua Portuguesa: uma abordagem pragmática. São Paulo: Papirus, 1995.

VAL, Maria das Graças. Redação e Textualidade. São Paulo: Martins Fontes, 1994.

ZILBERMAN, Regina. A Leitura no Brasil: sua história e suas instituições. Disponível em: <http:// www.unicamp.br/i e 1/memória/corpo/regina.html>. Acesso em: 4 out. 1998.

\section{ANEXO 1 - QUESTIONÁRIO}

Este instrumento tem por finalidade a coleta de dados para a realização de um trabalho acadêmico com o emprego da Metodologia da Problematização sobre o tema "Interpretação e Produção de Textos Por Alunos do Ensino Superior". Adiantamos que não há necessidade de identificação pessoal e garantimos o anonimato dos informantes, pelo que solicitamos que se sintam à vontade para responder as questões propostas.

\section{1- Renda Familiar}

( ) até 5 salários mínimos

( ) 6 a 10 salários mínimos

( ) acima de 10 salários mínimos

2- Quando você aprendeu a ler/ escrever?

( ) antes de ingressar na $1^{\mathrm{a}}$ série do ensino fundamental

( ) na $1^{\mathrm{a}}$ série

( ) após a $1^{\mathrm{a}}$ série 
3- Assinale quais elementos de sua família você percebe que têm o hábito de ler:
( ) Pai
( ) Mãe
( ) Irmãos
( ) Tios

( ) Outros. Quais? Você tem um local apropriado para leitura/estudo em sua casa?

( ) Sim ( ) Não

5- Selecione a opção que corresponde àquela para a qual você dedica a maior parte do seu tempo livre:

( ) $\mathrm{TV}$

( ) Esportes

( ) Música

( ) Leitura

( ) Cinema

( ) Cursos

( ) Lazer fora de casa

( ) Games/Internet

( ) Outros. Quais?

6- Quanto de seu tempo você dedica à leitura, diariamente?

( ) Nenhum

( ) Menos de 1 hora

( ) Mais de 1 hora

7- Que tipo de leitura você faz extra-classe?

( ) Revistas de informações gerais

( ) Revistas da área do curso de graduação

( ) Jornais

( ) Livros (não técnicos)

( ) Outros. Quais?

8- Sua família incentiva-o a ler?

( ) $\operatorname{Sim}$ ( ) Não

9- Durante sua escolaridade anterior, existiram situações importantes de incentivo à leitura? Em caso de resposta afirmativa, assinale em que período isto ocorreu.

( ) Entre a $1^{\mathrm{a}}$ e a $5^{\mathrm{a}}$ séries do ensino fundamental
( ) Entre a $6^{\mathrm{a}}$ e a $8^{\mathrm{a}}$ séries do ensino fundamental

( ) Durante o ensino médio

10- Nestas escolas onde você estudou, houve incentivo à produção escrita, através de trabalhos, redações e provas dissertativas? Em que período (s)?

( ) Entre a $1^{\mathrm{a}}$ e a $5^{\mathrm{a}}$ séries do ensino fundamental

( ) Entre a $6^{\mathrm{a}}$ e a $8^{\mathrm{a}}$ séries do ensino fundamental

( ) Durante o ensino médio

11 - Você teve ou tem algum professor que o estimula à leitura, seja verbalmente ou devido à sua própria atitude de leitor?
( ) $\operatorname{Sim}$
( ) Não

12- Você tem dificuldades para interpretar questões em provas ou outro tipo de leitura (textos, crônicas, livros, etc)?
( ) $\operatorname{Sim}$
( ) Não
( ) Um pouco

13- Você gosta de escrever?
( ) $\operatorname{Sim}$
( ) Não
( ) Um pouco

14- Qual tipo de atividade de escrita você mais aprecia?

( ) Poesia

( ) Carta

( ) Resumos para estudar

( ) Textos

( ) Estórias

( ) Outra. Qual?

15- Como você classifica sua escrita?

( ) Ruim

( ) Regular

( ) Boa

( ) Excelente 
